\title{
Virtual Intrinsic Value and the Principle of Organic Unities
}

\author{
By: Michael J. Zimmerman
}

Zimmerman, Michael J. Virtual Intrinsic Value and the Principle of Organic Unities. Philosophy and Phenomenological Research 59(3), 653-666, September 1999

Made available courtesy of Wiley-Blackwell http://www3.interscience.wiley.com/. ***Note: Figures may be missing from this format of the document

\begin{abstract}
:
This paper argues that Moore's principle of organic unities is false. Advocates of the principle have failed to take note of the distinction between actual intrinsic value and virtual intrinsic value. Purported cases of organic unities, where the actual intrinsic value of a part of a whole is allegedly defeated by the actual intrinsic value of the whole itself, are more plausibly seen as cases where the part in question has no actual intrinsic value but instead a plurality of merely virtual intrinsic values.
\end{abstract}

\section{Article:}

\section{Introduction}

In 1903, G. E. Moore introduced us to the principle of organic unities. In his words, this principle says: "The value of a whole must not be assumed to be the same as the sum of the values of its parts." ${ }^{1} \mathrm{He}$ was talking, of course, of intrinsic value. Since that time the principle has been frequently discussed, and it has usually been endorsed by those who have discussed it. ${ }^{2}$

Purported examples of organic unities abound. Prominent among these are apparently anomalous cases of pleasure and displeasure. Whereas pleasure has seemed to many to be intrinsically good, pleasure taken in something bad has not; and whereas displeasure itself has seemed intrinsically bad, displeasure taken in something bad has not. ${ }^{3}$ Note that such cases apparently cannot be construed simply as cases where the value of one part of the whole situation is counterbalanced by the value of another part. When malicious pleasure has as its object something that in fact does not exist but which the person in question believes to exist, this is almost as troubling, ethically, as when the object does exist. Yet in such a case we cannot appeal to the badness of the object as a counterbalance to the goodness of the pleasure. ${ }^{4}$ And, in the case of displeasure taken in something bad, there is no apparent candidate for a counterbalance to the badness of the displeasure, whether or not its object exists. Other anomalous cases involving pleasure and displeasure are those where the pleasure is undeserved and the displeasure deserved. ${ }^{5}$ Still other cases of alleged organic unities concern the order in which things occur, such as whether there is a progression from bad to good or from good to bad, whether goods are varied or occur in homogeneous groups, and so on. ${ }^{6}$

I think that the principle of organic unities is false, and in this paper I shall try to explain why. (More accurately: I think that the principle needs reformulation and that, when properly formulated, it should be declared false. The reason for this qualification will become apparent later.) One way to argue that the principle is false is to claim that those who diagnose certain 
situations as involving organic unities have overlooked relevant value-laden parts or aspects of the situation. For example, it is clear that our inclination to frown on pleasure taken in something bad is rooted in our assessment of the emotion as being somehow inappropriate to its object. Why, then, not say that this inappropriateness is a part or aspect of the overall situation that bears its own intrinsic value - a negative one - which counterbalances the goodness of the pleasure itself? $?^{7}$ I reject this approach. Even if a suitable account can be given of how the inappropriateness of the emotion is a bad part of the overall situation, still the appeal to counterbalancing seems to me in this case to be mistaken. For the badness of the inappropriateness (if it is bad) does not outweigh the goodness of the pleasure, and this is because (contrary to what this critic of the principle of organic unities says, and also to what most proponents of the principle say) the pleasure simply is not good.

Or so I shall argue. But I shall not attempt to do this by arguing that the pleasure in such a case is bad. ${ }^{8}$ For the pleasure is not bad, either. Nor is it neutral. To think that it must be one or the other of these is to overlook the fact that intrinsic value can be merely virtual rather than actual.

\section{The bearers of intrinsic value}

Whether or not the principle of organic unities is true depends of course on what sort of thing may be said to bear intrinsic value and to be such that it is either a whole or part of some whole. Although Moore himself never settled on an answer to this question, many answers have been proposed by others, most notably these: states of affairs, ${ }^{9}$ properties,${ }^{10}$ and facts. ${ }^{11}$ For reasons which space does not permit me to discuss here, I think we should say that states of individuals are the bearers of intrinsic value, where these are understood as concrete occurrences consisting in individuals exemplifying certain properties. Thus, and for example, when it is said that pleasure itself is intrinsically good, this would be understood as the claim that any and every episode of pleasure - any and every concrete occurrence that consists in someone's or something's being pleased-is intrinsically good. The property of being pleased is of course "doing the work" here, in that it is this that makes episodes of pleasure intrinsically good. Nonetheless, it is the episodes, and not the property, that bear this value. (Where the property is not exemplified, there is - to that extent - nothing intrinsically good, even though the property itself exists.)

States are to be individuated finely. Suppose that on some occasion Peter is undeservedly pleased. Do "Peter is pleased" and "Peter is undeservedly pleased" refer to one state or two? The answer is: two. (This stems from the fact that being pleased and being undeservedly pleased are themselves distinct properties.) This answer is in keeping with what both proponents and opponents of the principle of organic unities typically want to say. Proponents will typically say that Peter's being pleased is a good thing but his being undeservedly pleased is a bad thing. If there were just one state here and not two, how could this be so? One would have to resort to some such locution as "this state is intrinsically good under one description but not under another," and this seems incoherent; for how could something's intrinsic value be relative to some contingent description of it? And opponents such as myself will likewise wish to distinguish between the intrinsic value to be attributed to such states as Peter's being undeservedly pleased and that to be attributed to such states as Peter's being pleased. 
It is natural to say that a state such as Peter's being pleased is a part of the state consisting in his being undeservedly pleased. Perhaps this can be accounted for as follows: the existence of the former state is entailed by the existence of the latter. ${ }^{12}$ On this account, Peter's being pleased will also be a part of Peter's being pleased and Paul's being displeased, which again seems a natural thing to say. Perhaps it is not so natural to call this conjunction of states itself a state, but for convenience I shall so call it.

Finally, I shall assume that it is only states (including conjunctions of states) that have and can have intrinsic value. In saying this, I am agreeing at least partially with such proponents of the principle of organic unities as Roderick Chisholm and Noah Lemos, who believe that ascriptions of intrinsic value can all be made with respect to a single type of entity. But these authors appear implicitly to rely, in their discussion of this principle, on the further claim that all entities of the relevant type have intrinsic value. It is this claim that I think is false and whose falsity allows for a rejection of the principle. More precisely, I think it is false to say that all states have actual intrinsic value.

\section{Intrinsic value and favor}

Many philosophers have noted a connection between a state's having a certain intrinsic value and the fittingness of a certain attitude towards that state. There are variations among the proposals that have been offered, but the main gist seems to be this:

(I) Necessarily, state $S$ is intrinsically good [bad] if and only if the contemplation of $S$ and $\mathrm{S}$ alone requires that one favor [disfavor] $\mathrm{S} .{ }^{13}$

I have called the pro-attitude in question "favor" and the corresponding anti- attitude "disfavor," rather than use the more usual terms "love" and "hate, ${ }^{14}$ for the reason that the latter terms have too many irrelevant connotations and, moreover, suggest considerable intensity of feeling, whereas the former terms, being less common, are better suited to function as terms of art in this context.

I think that (I) should be accepted, and I will build my case against the principle of organic unities on the basis of it. I shall not seek to argue for (I) in turn but will have to rest content with the following observations.

First, when it is said that the contemplation of "S and $\mathrm{S}$ alone" requires a certain attitude, this is intended to indicate that it is just $\mathrm{S}$ and nothing else (in particular, not S's circumstances or S's consequences) that is the object of contemplation. It is this that will determine whether $\mathrm{S}$ is intrinsically worthy of favor or disfavor.

Secondly, the term "require" is borrowed from Chisholm, who takes it as primitive. ${ }^{15}$ In this he is followed by Lemos, who however qualifies the concept at issue as that of ethical requirement. ${ }^{16}$ This seems to me quite correct. Chisholm does not distinguish between ethical and non-ethical requirements. As illustrations of one thing requiring another, he gives the following:

...promise-making requires - or calls for-promise-keeping; being virtuous requires...being rewarded; the dominant seventh requires the chord of the tonic; one color in the lower left calls for a complementary color in the upper right. ${ }^{17}$ 
But while the first two illustrations concern ethics, the last two concern aesthetics. It may be that promise-making requires promise-keeping, but, if it does, this is an ethical matter. If one color calls for another that is complementary rather than incongruous, that is a matter of aesthetics. (One indication of what is at stake here is this. We would say that, if someone who contemplates something intrinsically good [bad] displays the required favor [disfavor], this is evidence of that person's ethical sensitivity.)

Thirdly, contrary to the assertions of some, ${ }^{18}$ it seems clear that favor and disfavor (however precisely these attitudes are to be understood, and I shall offer no account of them here) come in degrees. This permits us to refine (I) as follows:

(I') Necessarily, S is intrinsically good [bad] to a certain degree if and only if the contemplation of $\mathrm{S}$ and $\mathrm{S}$ alone requires that one favor [disfavor] $\mathrm{S}$ to a corresponding degree.

Thus (to use numbers in a purely ad hoc fashion): what is intrinsically good to degree 10 requires favor to a corresponding degree 10; what is intrinsically bad to degree 5 requires disfavor to a corresponding degree 5; and so on.

Fourthly, favor and disfavor are here to be construed as "overall" attitudes, attitudes that one takes "on balance" towards states. (This is analogous to giving a movie a vote of "thumbs up" or "thumbs down." While one might like the movie in certain respects and not in others, one's overall, on-balance assessment cannot be a vote of "both thumbs up and thumbs down.") Thus, if one favors a certain state, one doesn't disfavor it. But the reverse does not hold; for indifference is possible. One is indifferent (in the relevant sense) towards some state if and only if one neither favors nor disfavors it. (This is like a vote of "neither thumbs up nor thumbs down." Actually, this account of indifference is too rough; important qualification will be provided in the next section.) Given this notion of indifference, we can add to the foregoing account of intrinsic goodness and badness the following account of intrinsic neutrality:

(II) Necessarily, $\mathrm{S}$ is intrinsically neutral if and only if the contemplation of $\mathrm{S}$ and $\mathrm{S}$ alone requires that one be indifferent regarding $S .{ }^{19}$

\section{The isolation method}

Moore says:

The method which must be employed in order to decide the question 'What things have intrinsic value, and in what degrees?' has already been explained... In order to arrive at a correct decision on the first part of the question, it is necessary to consider what things are such that, if they existed by themselves, in absolute isolation, we should yet judge their existence to be good; and, in order to decide upon the relative degrees of value of different things, we must similarly consider what comparative value seems to attach to the isolated existence of each. ${ }^{20}$ 
Lemos calls this "ontological isolationism" and quite rightly says that it is unworkable; for every state is such that it cannot exist in isolation, since its existence implies the existence of countless other things. ${ }^{21}$ Lemos contrasts Moore's approach with that employed by Chisholm and exemplified in (I), (I'), and (II) above; he calls this "intentional isolationism." Even if no state can exist by itself, it can be contemplated in isolation, in that it and it alone can constitute the object of contemplation.

Moore employs the isolation method in order to argue against the hedonistic view that pleasure and pain are the only things of non-neutral intrinsic value. ${ }^{22}$ Others have followed suit. ${ }^{23}$ But most of these authors have nonetheless agreed with the hedonistic view that pleasure is intrinsically good (and pain intrinsically bad), even if such goodness (and badness) may be defeated within the context of a "wider" organic unity. ${ }^{24}$ This seems to me a mistake.

Consider ontological isolationism first. Since pleasure cannot exist all by itself, the best we can do here is to imagine a world as "bare" as possible apart from the fact that in it someone is pleased. I take it that this world would involve the pleasure's being neither appropriate nor inappropriate, neither deserved nor undeserved, since these would be further, ethically significant facts about the pleasure whose admission would be inconsistent with this "bare-bones" approach. ${ }^{25}$ But then Moore's claim that there is an organic unity when pleasure is taken in something bad cannot be sustained; ${ }^{26}$ for here we do not have an instance of that pleasure which has been independently identified as good constituting part of a whole that is not good. The pleasure independently identified as good is not an inappropriate pleasure; the pleasure that constitutes part of the whole in question is an inappropriate pleasure.

This sort of problem is obviated by intentional isolationism. Here it can be said that the pleasure that is independently identified by this method is the very same pleasure that constitutes part of the wider situation when pleasure is taken in something bad. And here the claim is that contemplation of the pleasure as such requires that one favor it. But why accept this claim? Once it is recognized that, whenever pleasure occurs, it must be either appropriate or inappropriate or neither, either deserved or undeserved or neither, it seems to me that, if appropriate or deserved pleasure is intrinsically good but inappropriate or undeserved pleasure is intrinsically bad, then what contemplation of pleasure as such requires is that one withhold either favor or disfavor or indifference. One should refrain from adopting any attitude towards it until all further relevant information (concerning appropriateness and desert and other matters, too, if they are relevant) has been supplied. Then and only then - once the "whole" situation has been presented for contemplation - should one adopt an attitude of favor, disfavor, or indifference towards it. If appropriate or deserved pleasure is intrinsically good but inappropriate or undeserved pleasure is intrinsically bad, then, I would say, pleasure as such is neither intrinsically good, nor intrinsically bad, nor intrinsically neutral.

Notice that I have talked here of indifference as an attitude, as favor and disfavor are attitudes. Indeed, I understand it to be an overall attitude, just as favor and disfavor are. In the last section I said that one is indifferent regarding some state if and only if one neither favors nor disfavors it. But now we can see that this isn't quite right; while the "only if" holds, the "if" does not. For it can happen that one neither favors nor disfavors some state because one lacks any overall attitude towards it, including that of indifference. Consider the movie analogy again. Suppose 
that one has not yet seen the movie; then one is not yet in a position to give it any evaluationnot a "thumbs up" (which is analogous to favor), nor a "thumbs down" (analogous to disfavor), nor even a "neither thumbs up nor thumbs down" (analogous to indifference). Thus indifference involves not merely the absence of favor and disfavor but the presence of a third attitude, and it is in this way that it can happen that one displays, indeed that one is required to display, none of the attitudes of favor, disfavor, and indifference.

I believe that what has just been said concerning pleasure can be applied to all cases where organic unities have traditionally been diagnosed. In all such cases, the "parts" of the "wholes" to which an intrinsic value has been ascribed are such that one ought in fact to withhold any overall attitude of favor, disfavor, or indifference towards them. Consider what is surely an oversimplified case. Suppose that the correct view were that a good person's experiencing pleasure is intrinsically good (regardless of any question of appropriateness), that a neither good nor bad person's experiencing pleasure is intrinsically neutral, and that a bad person's experiencing pleasure is intrinsically bad. What, on this view, should we take the intrinsic value of pleasure itself to be? My answer is: it has no such value. Consider a world in which nothing of intrinsic value occurs except that which is involved in a bad person's experiencing pleasure. I would say that, on the view in question, nothing good occurs; there is nothing such that the contemplation of it requires that one favor it.

Even if this is correct, though, and the pleasure in this case has no actual intrinsic value, it may be said to have a virtual intrinsic value. Understanding (I') and (II) to be statements that concern actual intrinsic value, we can now supplement them with the following:

(III) Necessarily, S is virtually intrinsically good [bad] to a certain degree if and only if, for some state $S^{\prime}$ whose existence entails that of $S$, the contemplation of $S^{\prime}$ and $S^{\prime}$ alone requires that one favor [disfavor] $S^{\prime}$ to a corresponding degree;

(IV) Necessarily, $S$ is virtually intrinsically neutral if and only if, for some state $S^{\prime}$ whose existence entails that of $S$, the contemplation of $S^{\prime}$ and $S^{\prime}$ alone requires that one be indifferent regarding $\mathrm{S}^{\prime}$.

In this case, then, the pleasure in question may be said to be virtually intrinsically bad. (In other cases, of course, a pleasure may be virtually good or neutral rather than bad. Thus virtual intrinsic value can vary in a way in which actual intrinsic value cannot. Wherever the exemplification of a certain property has a certain actual intrinsic value, any other exemplification of that property must have the same intrinsic value.) We can also say that a certain state merely has a certain virtual intrinsic value when it has that value but lacks any actual intrinsic value. On the view under discussion, any pleasure is as such merely virtually intrinsically valuable.

\section{Conditional intrinsic value}

It is apparent that I am taking actual intrinsic value to be in a certain sense unconditional, while virtual intrinsic value is conditional. In so doing, I am echoing the suggestions of others who have not been entirely won over by what Moore has had to say about organic unities. For example, W. D. Ross at times talks of pleasure as not being good in itself but rather as being prima facie good in itself. ${ }^{27}$ H. J. Paton has said something akin to this, ${ }^{28}$ and Chisholm has 
reported that both Franz Brentano and St. Thomas Aquinas at times made remarks in a similar vein. $^{29}$

I think that these remarks are all on the right track. But I hesitate to use either the term "conditional" or the term "prima facie" in this context because, associated as they so often are with the issues of conditional and prima facie obligation, they are liable to mislead. For example, Ross says:

Pleasure seems, indeed, to have a property analogous to that which we have previously recognized under the name of conditional or prima facie rightness. An act of promisekeeping has the property, not necessarily of being right but of being something that is right if the act has no other morally significant characteristic... And similarly a state of pleasure has the property, not necessarily of being good, but of being something that is good if the state has no other characteristic that prevents it from being good. ${ }^{30}$

This is suggestive but doesn't seem quite right, for it places undue emphasis on the possibility of pleasure's being virtually good and neglects the possibility that it be virtually neutral or bad. One indication of the disanalogy between prima facie rightness or obligatoriness on the one hand and virtual intrinsic value on the other is this. When an act is prima facie but not overall morally obligatory, it still has a certain moral value such that its nonperformance is cause for regret. ${ }^{31}$ But, I would urge, it is emphatically not the case that, when a certain malicious pleasure has been avoided, there is any cause for regret. ${ }^{32}$

\section{Objections to the account}

Several objections may be raised against the account that I have given of virtual intrinsic value. I shall consider four.

First, it might be objected that, even on my account, the principle of organic unities is true. Suppose that $S^{\prime}$ is actually intrinsically good but that no other state, whose existence is entailed by that of S', is actually intrinsically good; that is, any such state is merely virtually intrinsically good. Then the intrinsic value of $S^{\prime}$ is not the same as the sum of the intrinsic values of its parts. Therefore the principle is true.

In response, let me remind you that I said that the principle of organic unities needs reformulation. It must be acknowledged that, as formulated by Moore and as quoted at the outset of this paper, the principle is indeed shown to be true by a case of the sort just given; but this is trivial. Moore presumably formulated the principle as he did because he thought that all parts of all wholes have actual intrinsic value. On this assumption, his formulation of the principle is sufficient to capture what he took to be his main insight, namely, that the intrinsic values of parts can be not just counterbalanced but defeated by the intrinsic value of a whole. It is this idea that I am opposing in this paper. Given the possibility of merely virtual intrinsic value, however, the principle of organic unities needs to be reformulated in order to capture this idea of defeat. I propose the following formulation (for the time being - but see the final section):

The actual intrinsic value of a state must not be assumed to be the same as the sum of the actual intrinsic values of those states that are a part of it and have such value. 
My purpose has been to cast doubt on the existence of organic unities so understood.

A second objection is that I have provided no account of which sorts of states have actual intrinsic value and which have merely virtual intrinsic value. ${ }^{33}$ I plead guilty, for I have not attempted to supply even part of a substantive axiology. For purposes of illustration, I have suggested that pleasure as such may have merely virtual intrinsic value whereas undeserved pleasure in the bad is perhaps actually intrinsically bad. But I certainly have not argued for this view; that would be an entirely separate task. My failure to undertake this task, however, affords no reason to deny the legitimacy of the distinction between actual and virtual intrinsic value. Given this distinction, one can envision a gamut of axiologies, ranging from the extremely atomistic (according to which all states have actual intrinsic value, none have merely virtual intrinsic value) to the extremely holistic (according to which the only state with actual intrinsic value is the actual world). I suspect that the true axiology lies somewhere in between (so that while some states have actual intrinsic value - and the intrinsic value of conjunctions of these states is to be computed simply by summation - other states have merely virtual intrinsic value), but this claim cannot be investigated here.

A third objection is that the present approach violates what is sometimes called the principle of universality. ${ }^{34}$ This principle may be put as follows: the intrinsic value of a part of an intrinsically valuable whole does not depend on the other parts of the whole. It is to be contrasted with the principle of conditionality, which may be put as follows: the intrinsic value of a part of an intrinsically valuable whole does depend on the other parts of the whole. Lemos is one author who declares the former principle true and the latter false, and he accuses Ross of being committed to the latter rather than the former. But whether or not this is true of Ross, it is not true of me. I agree that the intrinsic value - that is, the actual intrinsic value - of a state cannot be conditional on the state's circumstances. My claim is that states that have merely virtual intrinsic value have no actual intrinsic value, and that this is so regardless of the circumstances of such states.

A final and, to my mind, much stronger and more interesting objection is one that has been offered by Lemos:

The chief difficulty with Ross's view [that pleasure as such is merely prima facie intrinsically good] is that it misses what apparently makes so offensive the prosperity of the wicked... What is it that makes the wicked man's being happy...so offensive? I suggest that it is offensive precisely because we think that the wicked man has a good that he deserves not to have. Contrary to Ross, the judgment that the prosperity of the wicked is not good...presupposes the judgment that his being pleased is good; it is a good that is contrary to what he deserves. ${ }^{35}$

There is undoubtedly something correct in this. When a wicked man prospers, he benefits undeservedly, and that is what seems so offensive. And it is not just he who sees his prosperity as being beneficial to him; we do too. But I think we should resist saying that there is anything intrinsically good involved in this benefit. His prosperity, being beneficial to him, might be said to be good for him; but it doesn't follow that it is good simpliciter. It is not clear to me just how 
this distinction is to be understood, but we can gain at least partial insight into it by recalling that, when it is said that contemplation of what is good requires that one favor it, it is ethical requirement that is at issue. Consider Wilfred's being both wicked and happy. Lemos would say that contemplation of this state (and this state alone) requires that we disfavor it, whereas contemplation of Wilfred's being happy requires that we favor it. Although I am prepared (for the sake of argument) to accept the former claim, I reject the latter. Notice that it is surely rational (in some sense) for Wilfred himself not just to prefer his being happy to his not being happy, but also to prefer his being wicked and happy to his being wicked and not happy; but even he (like everyone else) is ethically required to prefer his being wicked and not happy to his being wicked and happy. This indicates that the sort of rationality at issue here is distinct from ethical requirement, and I can therefore agree that it is rational for the wicked Wilfred to prefer his being happy to his not being happy (and that it is at least partly in virtue of this fact that his being happy is good for him), without agreeing that everyone is ethically required to prefer his being happy to his not being happy (and so without agreeing that his being happy is intrinsically good).

\section{Extensions of the account}

In a previous paper I made no mention of "virtual" intrinsic value, but I did talk of the possibility of certain states being "evaluatively incomplete," that is, entirely lacking in (actual) intrinsic

value. ${ }^{36}$ I applied this to cases where organic unities have been diagnosed, but I applied it to other cases too. Suppose that a very simple form of hedonism were true, according to which (roughly) all pleasures and only pleasures are intrinsically good, and the goodness of pleasures cannot be defeated by their being embedded in any wider context. Even on such a supposition, it seems to me, one should hesitate to say that a state consisting in someone's being pleased is itself actually intrinsically good. After all, what is good is presumably good to a certain determinate extent (I suppose that this could be challenged, perhaps on the basis that some goods are incommensurable with others, but I will let this pass), and to what extent is the state in question good? Well, it depends, doesn't it, on the context or situation at hand. If Peter is pleased to degree 10 (to use numbers again in a purely ad hoc fashion) then, on this simple hedonism, there would be reason to say that the state consisting in his being pleased to degree 10 is intrinsically good and, more particularly, good to degree 10. But what of the state consisting simply in Peter's being pleased? How good is it? My answer, of course, is that this state is, even on the simple hedonism being presupposed, not actually good at all; rather, it is merely virtually good (to degree 10). ${ }^{37}$

We may treat disjunctive states (such as Peter's being either pleased or displeased) similarly. Committed to the view that all states have actual intrinsic value, Chisholm has gone to great lengths to establish the proper criterion for determining the intrinsic value of disjunctive states. ${ }^{38}$ His view, whose details I shall not provide here, has the strange consequence that a disjunctive state consisting in the disjunction of a very good state and a slightly bad state has the same intrinsic value as the disjunction of a slightly good state and a very bad state (namely, nil); it also implies that the disjunction of a slightly good state and another slightly good state has the same intrinsic value as the disjunction of a slightly good state and a very good state (namely, the value of the slightly good state). All of this can be avoided by noting that a disjunctive state cannot exist without one or other of its disjuncts existing and that, therefore, we can ascribe one or more virtual intrinsic values to the disjunctive state (these values corresponding to the actual intrinsic 
values, if any, of its existing disjuncts) without having to try to settle on a single actual intrinsic value for the disjunction itself.

\section{Basic intrinsic value}

When responding to the first objection in Section 6, I proposed that the principle of organic unities be reformulated as follows:

The actual intrinsic value of a state must not be assumed to be the same as the sum of the actual intrinsic values of those states that are a part of it and have such value.

But in fact this won't quite do, either. When trying to determine the actual intrinsic value of a suitably "wide" state, one cannot do this simply by summing up the actual intrinsic values, if any, of its "component" states, for this would result in serious distortion. Suppose that Si is intrinsically good to degree $10, \mathrm{~S} 2$ to degree 20 , and S3 to degree 30 . Then, it seems, we may talk not only of 51 and $\mathrm{S} 2$ and $\mathrm{S} 3$ each individually being a component of S1\&S2\&S3, but also of $\mathrm{S} 1 \& S 2$ and $\mathrm{S} 1 \& 53$ and S2\&S3 likewise being components of S1\&S2\&S3. Perhaps we can also talk of $\mathrm{S} 1 \& S 2 \& S 3$ being a component of itself. The sum value of all these components is 240 - far higher than the value of 60 that we are intuitively moved to assign to S1\&S2\&S3. Our intuition is based, of course, on the tacit assumption that S1 and S2 and S3 are not just evaluatively complete but basically so, whereas this is not true of the other parts of S1\&S2\&S3.

I think that the notion of basic intrinsic value can be fairly straightforwardly understood, once it is acknowledged that not all states have actual intrinsic value. We can say the following:

$\mathrm{S}$ has basic intrinsic value $=\mathrm{df}$. $\mathrm{S}$ has actual intrinsic value, and no proper part of $\mathrm{S}$ has actual intrinsic value. ${ }^{39}$

On this basis, we can reformulate the relevant principle of organic unities yet again, as follows:

The actual intrinsic value of a state must not be assumed to be the same as the sum of the basic actual intrinsic values of those states that are a part of it and have such value. ${ }^{40}$

I cannot claim to have shown this principle false, but I hope that I have given good reason to doubt that it is true. ${ }^{41}$

\section{Footnotes}

1. Moore (1903), p. 28, italics deleted.

2. See especially, in recent years, Chisholm (1986) and Lemos (1994).

3. See Brentano (1969), pp. 90-91 (this book was first published in the original German in 1889); Moore (1903), pp. 208 ff.; Chisholm (1986), pp. 76 ff.; Lemos (1994), pp. 35 ff.

4. See Chisholm (1986), p. 76.

5. See Ross (1930), p. 72; Chisholm (1968-69), p. 30.

6. See Chisholm (1986), pp. 70 ff.; Lemos (1994), pp. 37 ff., 199-200.

7. Perhaps Brentano has this in mind at Brentano (1969), p. 23, n. 1. 
8. This is what is apparently implied in Dancy (1993), pp. $61 \mathrm{ff}$. Yet Dancy declares pleasure in other cases to be good. This seems to me inconsistent with how the notion of intrinsic value is to be understood, but the issue is too complex to address here.

9. See Chisholm (1986), pp. $60 \mathrm{ff}$.

10. See Butchvarov (1989), p. 14.

11. See Ross (1930), p. 137; Lemos (1994), pp. 22-23.

12. This corresponds to suggestions made in Chisholm (1986), p. 73, and Lemos (1994), pp. 33-34. Just what constitutes the sort of entailment in question is a difficult issue that I shall not try to resolve here. There is reason to think it must be more than simply strict implication.

13. Cf. Brentano (1969), p. 18; Ross (1939), p. 279; Ewing (1948), Ch. 5; Chisholm (1986), Ch. 5; Lemos (1994), Ch. 1; and Goldstein (forthcoming).

14. See Brentano (1969), pp. 18, 137 ff.; Chisholm (1986), Chs. 3, 5; Lemos (1994), pp. 6 ff. Lemos makes mention of "favor" and "disfavor" and employs them on occasion. Blanshard also uses these terms in Blanshard (1961), pp. $280 \mathrm{ff}$.

15. Chisholm (1964) and (1986), p. 52.

16. Lemos (1994), p. 12.

17. Chisholm (1964), p. 147.

18. See Brentano (1969), pp. 25-26; Chisholm (1986), pp. 19-20; Lemos (1994), p. 12.

19. On pp. 13-14 of Lemos (1994) an interesting distinction is drawn between four types of neutrality. For reasons that space does not permit me to develop, I decline to follow Lemos's lead here.

20. Moore (1903), p. 187. Cf. Moore (1912), p. 102, and Ross (1930), pp. 68-69,134.

21. Lemos (1994), pp. 10-11.

22. Moore (1903), Ch. 6; (1912), Ch. 7.

23. E.g., Ross (1930), Ch. 5; Chisholm (1986), p. 60; Lemos (1994), Ch. 6.

24. Moore (1903), pp. 87 ff.; Chisholm (1986), pp. 76 ff.; Lemos (1994), pp. 36 ff.

25 . Here "inappropriate" and "undeserved" mean something stronger than just "not appropriate" and "not deserved."

26. Moore (1903), pp. 208-9.

27. Ross (1930), p. 138.

28. Paton (1942), p. 122.

29. Chisholm (1986), pp. 96-97, including n. 6.

30. Ross (1930), p. 138.

31. Ross (1930), p. 28.

32. Ironically, Chisholm is in agreement with this. See Chisholm (1986), p. 79.

33. Chisholm mentions this in Chisholm (1986), pp. 81-82, n. 22.

34. Cf. Lemos (1994), pp. 32-33.

35. Lemos (1994), pp. 43-44. See also Goldstein (1989), p. 269, for a very similar point.

36. Zimmerman (1983). In that paper I took abstract states of affairs to be the bearers of intrinsic value, contrary to the position I take in this paper.

37. That is, it has a virtual intrinsic value of 10 . Note that this is consistent with saying that it may also have a different virtual intrinsic value (since it may be part of some state, other than that of Peter's being pleased to degree 10, that has an actual intrinsic value other than $10)$.

38. Chisholm (1975). 
39. This isn't quite adequate, since every state seems infinitely temporally divisible. But this is a complication that I shall ignore here.

40. On basic intrinsic value, and how this notion can be put to a variety of uses, see Feldman (draft).

41. My thanks to Krister Bykvist, Irwin Goldstein, Joshua Hoffman, Noah Lemos, Howard Sobel, and some anonymous referees for very penetrating and helpful comments on earlier drafts.

\section{Bibliography}

Blanshard, Brand (1961). Reason and Goodness. London: George Allen and Unwin.

Brentano, Franz (1969). The Origin of Our Knowledge of Right and Wrong, translated by Roderick M. Chisholm and Elizabeth H. Schneewind. New York: Humanities Press.

Butchvarov, Panayot (1989). Skepticism in Ethics. Indianapolis: Indiana University Press.

Chisholm, Roderick M. (1964). "The Ethics of Requirement." American Philosophical Quarterly 1: 147-53. .(1968-69). "The Defeat of Good and Evil." Proceedings of the American Philosophical Association 42: 21-38.

. (1975). "The Intrinsic Value in Disjunctive States of Affairs." Nous 9: 295-308. . (1986). Brentano and Intrinsic Value. Cambridge: Cambridge University Press.

Dancy, Jonathan (1993). Moral Reasons. Oxford: Blackwell.

Ewing, A. C. (1948). The Definition of Good. London: Routledge and Kegan Paul.

Feldman, Fred (1986). Doing the Best We Can. Dordrecht: D. Reidel. . (draft). "Basic Intrinsic Value."

Goldstein, Irwin (1989). "Pleasure and Pain: Unconditional, Intrinsic Values." Philosophy and Phenomenological Research 50: 255-76. . (forthcoming). "The Problematic Reality of Value."

Lemos, Noah (1994). Intrinsic Value. Cambridge: Cambridge University Press.

Moore, G. E. (1903). Principia Ethica. Cambridge: Cambridge University Press. . (1912). Ethics. Oxford: Oxford University Press.

Paton, H. J. (1942). "The Alleged Independence of Goodness." In The Philosophy of G. E. Moore, edited by P. A. Schilpp. Chicago: Northwestern University.

Ross, W. D. (1930). The Right and the Good. Oxford: Oxford University Press. . (1939). Foundations of Ethics. Oxford: Clarendon Press.

Zimmerman, Michael J. (1983). "Evaluatively Incomplete States of Affairs." Philosophical Studies 43: 211-24. 